\title{
High Prevalence of Back Pain and Axial Spondyloarthropathy in Patients with Hidradenitis Suppurativa
}

\author{
Sylke Schneider-Burrus ${ }^{a}$ Ellen Witte-Haendel ${ }^{b, c}$ Demetrios Christou ${ }^{b, c}$ \\ Benedetta Rigoni $^{d}$ Robert Sabat ${ }^{\text {b, } c}$ Gerd Diederichs ${ }^{d}$ \\ aDepartment of Dermatology and Allergy, ${ }^{\mathrm{b}}$ Interdisciplinary Group of Molecular Immunopathology, \\ Dermatology/Medical Immunology, 'Psoriasis Research and Treatment Center, and dDepartment of Radiology, \\ Charité University Hospital, Berlin, Germany
}

\section{Key Words}

Hidradenitis suppurativa $\cdot$ Acne inversa $\cdot$ Axial

spondyloarthropathy $\cdot$ Sacroiliac joints $\cdot$ Sacroiliitis $\cdot$ Tumour necrosis factor

\begin{abstract}
Background: Hidradenitis suppurativa (HS) is a chronic inflammatory disease, causing fistulating sinuses in the intertriginous skin of axillary, genitofemoral and perianal sites. Objective: As other chronic inflammatory diseases, e.g. psoriasis, are frequently associated with spondyloarthropathies (SpA), the goal of this study was to quantify the prevalence of back pain and SpA in HS patients. Methods: A prospective questionnaire survey in $100 \mathrm{HS}$ patients and a retrospective evaluation of pelvic magnetic resonance imaging (MRI) scans in $46 \mathrm{HS}$ patients were conducted. Results: $71 \%$ of HS patients were suffering from back pain. There was no difference between age at onset of HS, disease duration, body mass index (BMI), or disease severity between HS patients with and without back pain. Evaluating pelvic MRI scans, $32.6 \%$ of HS patients showed signs of chronic SpA and $39.1 \%$ signs of active SpA. Again, no significant differences between patients with/without SpA were found regarding age at time of MRI, age at onset of HS, disease duration, smoking habits, and BMI.
\end{abstract}

Furthermore, there was no correlation between these parameters and the degree of SpA. Limitations: Only patients with moderate/severe HS (Hurley stage II and III) in genitofemoral/ perianal sites were analysed via MRI scans. Conclusion: Back pain and SpA are very common among patients with moderate/severe HS. Neither medical history nor clinical parameters provide hints for the presence of SpA.

(c) 2016 S. Karger AG, Basel

\section{Introduction}

Hidradenitis suppurativa (HS, also referred to as acne inversa) is a chronic inflammatory disease of terminal hair follicles, which affects the intertriginous skin of axillary and inguinoperineal sites $[1,2]$. It is estimated that approximately $1 \%$ of the general population suffer from HS $[3,4]$ with a higher prevalence of up to $4 \%$ in young females [3].

The aetiology of HS is unknown so far. Smoking, obesity, hormonal factors, and a putative genetic background

Robert Sabat and Gerd Diederichs contributed equally to this work and are co-last authors.

\section{KARGER}

E-Mail karger@karger.com

www.karger.com/drm
C 2016 S. Karger AG, Basel

$1018-8665 / 16 / 2325-0606 \$ 39.50 / 0$
Sylke Schneider-Burrus

Department of Dermatology and Allergy, Charité University Hospital Charitéplatz 1

DE-10117 Berlin (Germany)

E-Mail sylke.schneider@ charite.de 


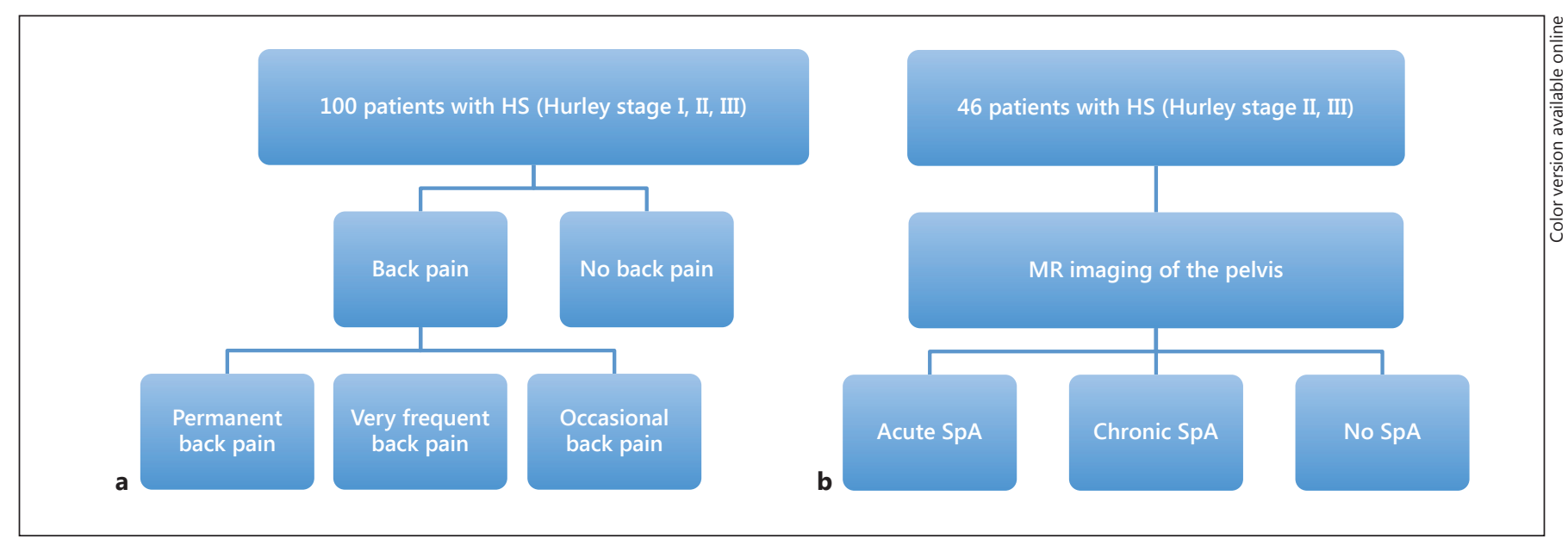

Fig. 1. a, b Flow chart of the Methods.

Table 1. Characteristics of patients of the questionnaire survey study group and the MRI study group

\begin{tabular}{lcl}
\hline & Questionnaire survey & MRI study \\
\hline Age, years & $38.77 \pm 1.00$ & $41.07 \pm 1.74$ \\
Females, \% & 66 & 43.48 \\
Males, \% & 34 & 56.52 \\
Age at onset, years & $25.61 \pm 1.05$ & $29.11 \pm 1.92$ \\
Duration of disease, years & $13.26 \pm 0.94$ & $12.98 \pm 1.65$ \\
BMI & $29.44 \pm 0.68$ & $28.22 \pm 0.65$ \\
\hline
\end{tabular}

may play a role in disease development and/or course. Initially, hyperplasia of the follicular epithelium leads to stasis in the hair follicle unit, formation of subcutaneous nodules, and propagation of bacteria [5-7]. Later, the nodules spontaneously rupture or melt, forming painful deep dermal abscesses. The content of ruptured nodules strengthens inflammation that further supports purulent exudate formation. In the late stage, lesions are characterized by painful, fistulating sinuses and large indurated inflammatory plaques with extensive scarring [5]. At the molecular level, the HS lesions are characterized by strong inflammation with various aspects of immune dysregulation [8].

In addition to the cutaneous symptoms, a high proportion of HS patients suffer from severe metabolic alterations $[9,10]$. These alterations include obesity, elevated fasting blood glucose levels and dyslipidaemia, and may be caused or potentiated by chronic inflammation observed in HS patients.

Spondyloarthropathy in Hidradenitis Suppurativa
Several chronic inflammatory diseases affecting epithelial tissues like psoriasis, Crohn's disease, or colitis ulcerosa are frequently associated with spondyloarthropathy (SpA) [11], which may significantly reduce the quality of life of these patients.

Cigarette smoking has been suggested to be associated with the progression of SpA and might even have a dosedependent impact on the course of structural damage in axial SpA [12,13]. Moreover, an association between obesity and SpA has been communicated, with obesity being associated with a poor clinical outcome [14].

Since an association of $\mathrm{HS}$ and $\mathrm{SpA}$ is largely unknown so far, the aim of this study was to assess the prevalence of back pain in a large cohort of HS patients by means of questionnaires and to analyse radiological signs for $\mathrm{SpA}$ in magnetic resonance imaging (MRI) scans of the pelvis.

\section{Methods}

For further details, see the supplementary materials (for all online suppl. material, see www.karger.com/doi/10.1159/000448838) [15-20] (fig. 1; table 1).

\section{Results}

\section{Prospective Questionnaire Analysing the Prevalence of} Back Pain

Analysing the survey in 100 patients with HS, we learned that $71 \%$ of HS patients were afflicted by back pain (fig. 2). 33.8\% of affected patients reported very frequent or permanent pain, $66.2 \%$ of the affected patients 
suffered from occasional pain. In $76.1 \%$ of HS patients the back pain was located in the lumbar region (fig. 2).

There were no differences in age at onset of HS, disease duration, smoking incidence, and frequency of a positive HS family history between HS patients without and with back pain or patients with occasional, very frequent or permanent pain (data not shown). The assessment of clinical parameters revealed no differences in body height, body weight, body mass index (BMI), and disease severity between HS patients with or without back pain either.

The only significant difference between clinical parameters of patients without back pain, patients with occasional pain, and patients with very frequent or permanent pain was found concerning the patients' height. In fact, patients suffering from very frequent or permanent pain were shorter than patients with occasional or no pain $(169.5,176.2$, and $174.3 \mathrm{~cm}$, respectively, $\mathrm{p}=0.003)$. However, there was no significant difference regarding weight between HS patients without pain and with very frequent or permanent pain $(83.2,93.9$, and $86.5 \mathrm{~kg}$, respectively), ruling out body mass influences on the identified association of HS with back pain.

\section{Retrospective MRI Study Analysing the Prevalence of \\ SpA}

In order to identify the reason for the back pain in HS, MRI scans of the pelvis that had been undertaken in HS patients as preparation for the surgical excision of HS were re-evaluated for abnormalities in the sacroiliac joints. In $56.5 \%$ of these patients typical changes indicative of SpA were found (fig. 3a). A total of $39.1 \%$ of investigated HS patients showed characteristics of acute inflammation (fig. 3a, 4a), consisting in various degrees of joint effusion, synovitis, erosions and subchondral oedema. In most cases, these were mild to moderate alterations (table 2, fig. 3b). Furthermore, MRI scans of $32.6 \%$ of HS patients showed signs of chronic SpA activity at the sacroiliac joints (fig. $3 \mathrm{a}, 4 \mathrm{~b}$ ). These signs were again various degrees of the manifestation of subchondral sclerosis and widening or narrowing of the joint space as far as definitive ankylosis bilaterally. In most cases, the chronic alterations were of first grade (table 2, fig. 3b). Interestingly, $15.2 \%$ of HS patients simultaneously presented signs of acute and chronic SpA (fig. 3a).

Relevant signs for osteoarthritis, posttraumatic joint alterations, osteitis condensans ilii, or pyogenic sacroiliitis were not found in any patient of this study.

The evaluation of available anamnestic parameters of the MRI cohort showed no significant differences between HS patients with and without SpA regarding the

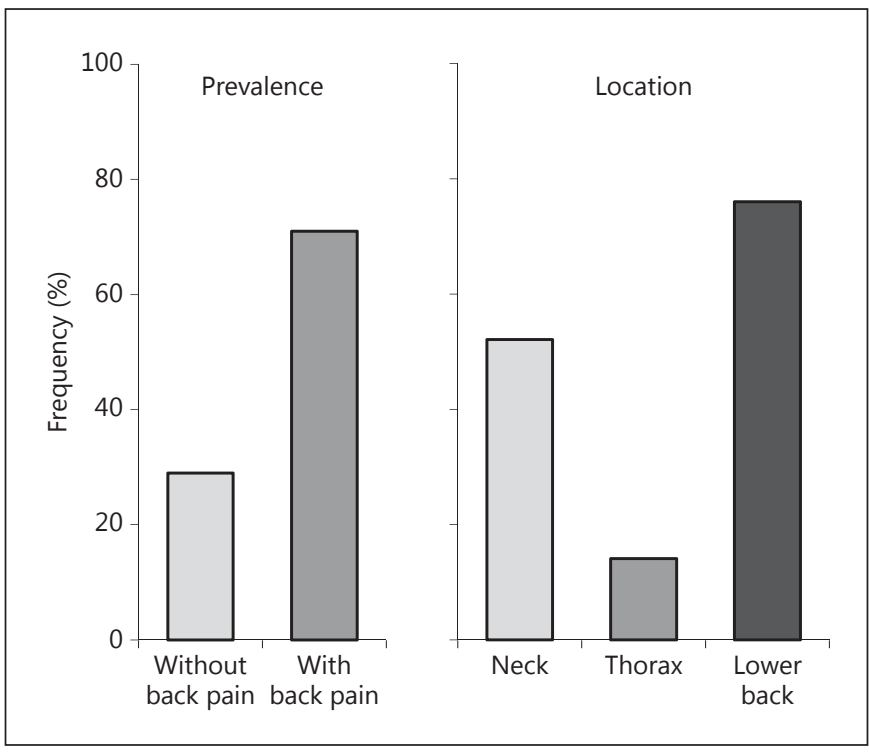

Fig. 2. Back pain is a condition commonly reported by HS patients. The prevalence and localization of back pain were investigated by a questionnaire survey performed on $100 \mathrm{HS}$ patients. Frequencies are presented as the percentage of total patients.

Table 2. Frequency of the different degrees of acute and chronic inflammation in patients with HS

\begin{tabular}{lll}
\hline & $\begin{array}{l}\text { Patients with acute } \\
\text { inflammation }\end{array}$ & $\begin{array}{l}\text { Patients with chronic } \\
\text { inflammation }\end{array}$ \\
\hline Grade 1 & 9 & 12 \\
Grade 2 & 6 & 2 \\
Grade 3 & 1 & 1 \\
Grade 4 & 2 & 0 \\
\hline
\end{tabular}

following parameters: age at time of MRI, age at onset of HS, disease duration, smoking habits, and ethnicity (table 3). The assessment of clinical data also demonstrated similar levels for body height, body weight, BMI, and disease severity between HS patients with and without SpA. For a limited number of patients, further clinical data were available, such as white blood cell count $(n=33)$ and C-reactive protein $(n=25)$. Both of these inflammatory markers were higher in the SpA group, but these differences were not significant, possibly due to the small number of samples.

Furthermore, there was no correlation between any of the parameters above and the degree of SpA (data not shown). 


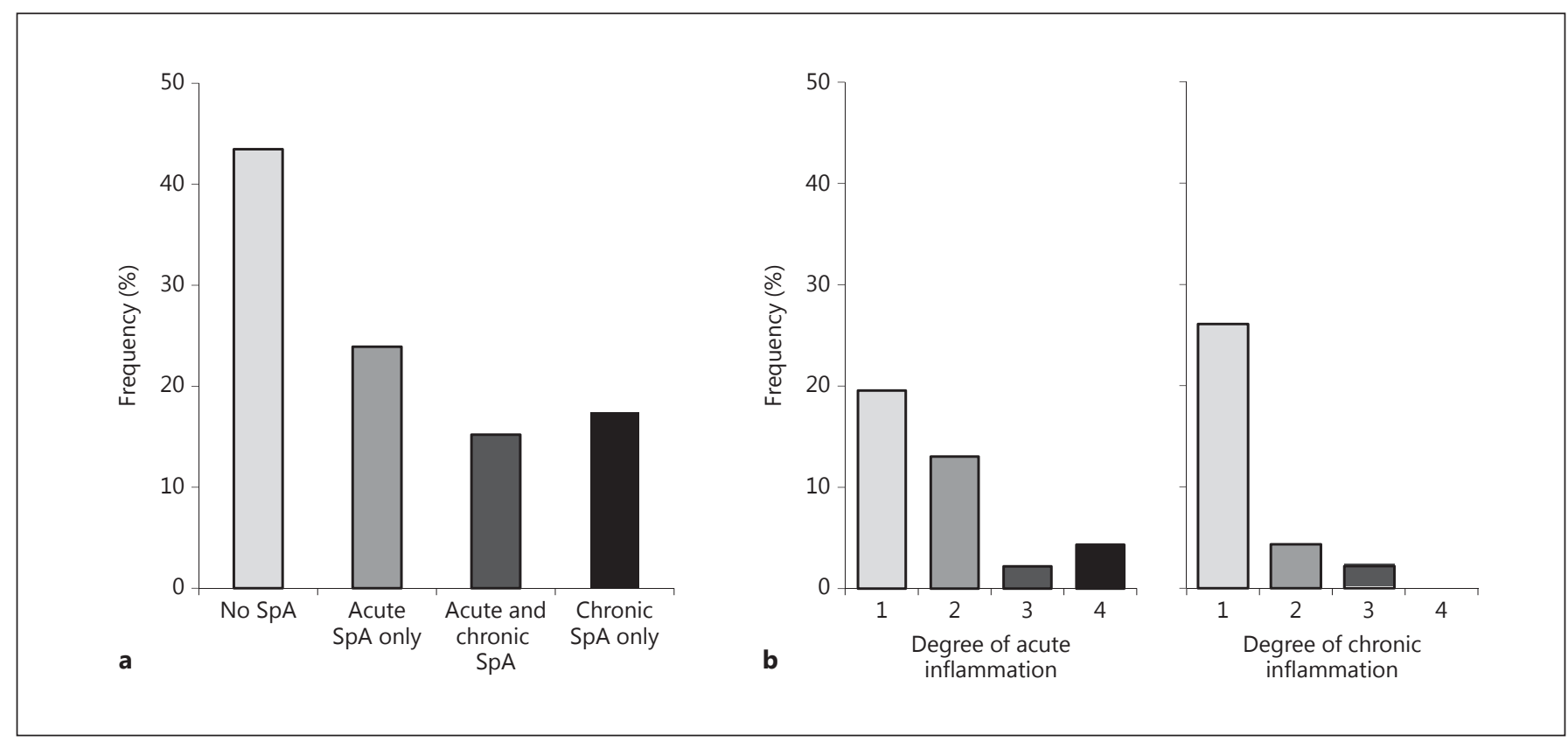

Fig. 3. SpA is a common phenomenon in HS patients. MRI scans were made in $46 \mathrm{HS}$ patients as part of preparations for the subsequent surgical procedure. Patients were not evaluated for back pain or clinical signs of arthritis before MRI. a Prevalence of HS patients with signs of acute, acute and chronic, or chronic SpA alterations determined by MRI. b Frequency of HS patients according to severity of SpA.

\section{Discussion}

In this current study we analysed the prevalence of back pain in patients suffering from HS and demonstrated that back pain is common in HS patients. In fact, $71 \%$ of HS patients suffer from back pain. Sacroiliitis as the possible cause of lower back pain may be difficult to detect, as it is commonly mistaken for other entities such as disc herniations or osteoarthritis. Interestingly, $56.5 \%$ of non-preselected HS patients in our investigation harboured clear radiological signs of SpA pointing to a substantial proportion in view of the overall prevalence of SpA being 1\% [21].

An association between HS and SpA was a matter of suggestion by few publications in the past. Rosner et al. [22] were the first to report cases of SpA in HS patients. This initial description from 1982 was followed by a number of case reports and few small case series [21, 23-26]. The observed radiographic alterations in HS patients were described as indistinguishable from those of other seronegative forms of SpA [27]. Our precise MRI analyses $[28,29]$ disclosed a surprisingly high number of typical changes suggesting SpA-related sacroiliitis in $56.5 \%$ of the patients.
Table 3. Characteristics of patients with and without radiological signs of SpA

\begin{tabular}{lccc}
\hline & $\begin{array}{c}\text { Patients without } \\
\text { signs of SpA }\end{array}$ & $\begin{array}{c}\text { Patients with } \\
\text { signs of SpA }\end{array}$ & p value \\
\hline Number of patients & 20 & 26 & \\
Sex ratio female/male & $8 / 12$ & $12 / 14$ & 0.676 \\
Age at MRI, years & $40.8 \pm 10.8$ & $41.3 \pm 12.8$ & 0.610 \\
Hurley classification & & & 0.334 \\
$\quad$ I & $0(0 \%)$ & $0(0 \%)$ & \\
$\quad$ II & $15(75 \%)$ & $16(62.5 \%)$ & \\
III & $5(25 \%)$ & $10(38.5 \%)$ & \\
Ethnicity & & & 0.116 \\
$\quad$ German & 20 & 23 & 0.205 \\
$\quad$ Turkish & 0 & 2 & 0.373 \\
$\quad$ African-European & 0 & 1 & 0.457 \\
Current smokers $(\mathrm{n}=28), \%$ & 81.8 & 92.9 & \\
\hline
\end{tabular}

The $\mathrm{p}$ values calculated by the $\chi^{2}$ test (sex distribution, Hurley classification, ethnicity, smoking habit) or Mann-Whitney U test (age) are indicated. 
Fig. 4. Examples of acute and chronic sacroiliitis in HS patients. Paracoronal T1weighted MR images with fat saturation after intravenous injection of radiopaque material in two different HS patients show characteristics of acute sacroiliitis. a Image obtained from a 53-year-old female patient, graded Hurley stage III. White arrows mark strong enhancement in the para-articular bone marrow indicating acute sacroiliitis on both sides of grade 4 (grade 4 acute arthritis). b Image obtained from a 37-year-old female patient, graded Hurley stage II. A moderate signal increase in the para-articular bone marrow only on the left side is found, which was staged as a grade 3 (grade 3 acute arthritis). Also, on both sides signs of chronic sacroiliitis are shown: there is pronounced bilateral para-articular sclerosis (white arrowheads) and beginning ankylosis on the right side (grey arrow, grade 3 chronic arthritis).
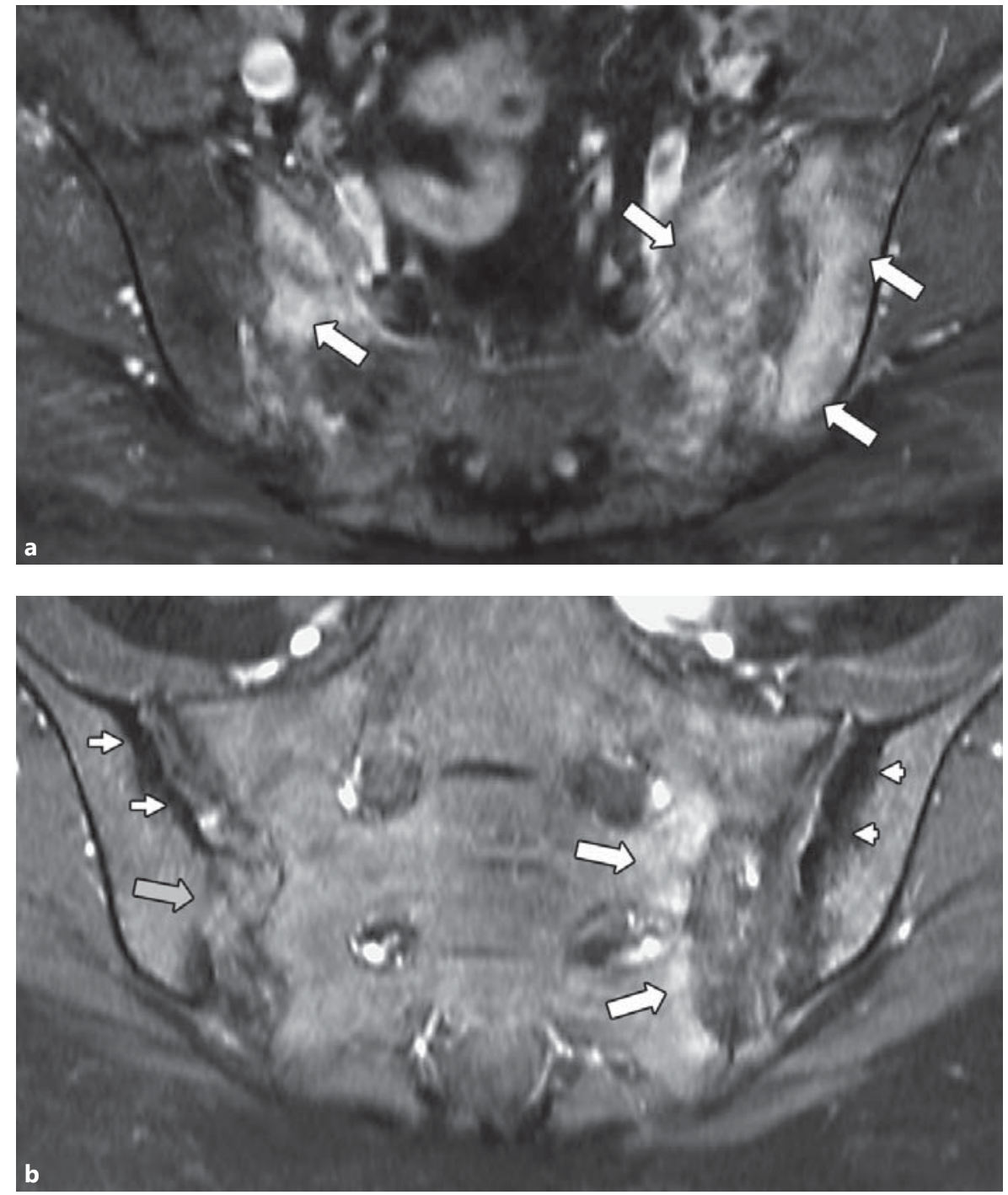

Most of the case series and case reports in the past suggested the association of HS and SpA to mainly concern male African-American or Afro-Caribbean patients [22, $25,26,30]$. In our study we included 1 male patient of African ancestry, 2 male Turkish patients and 43 patients of German origin. 23 of the latter had radiological signs of $\mathrm{SpA}$, indicating that the high risk for developing SpA among HS patients is independent of their ancestry.

Recently the first prospective study investigating the presence of SpA in patients with HS has found an elevated overall rate of 3.7\% [31]. Within the screened 640 patients with HS, 184 (29\%) had musculoskeletal symptoms, considerably fewer than in the present study. 15 patients underwent MRI of the sacroiliac joints and the spine, of whom $20 \%$ showed active inflammatory lesions in the spine, $20 \%$ in the sacroiliac joints and $20 \%$ structural lesions of the sacroiliac joints. 31 additional patients were investigated with conventional radiographs, showing radiological signs of sacroiliitis (10 patients) and syndesmophytes (4 patients). Since only patients with clinical signs of inflammatory rheumatological diseases were screened by radiography/MRI, the rate of alterations in the sacroiliac joint in the remaining 594 (asymptomatic) patients remains unknown.

Our finding that $\mathrm{SpA}$ is dramatically common in patients with severe and moderate HS leaves us with two open questions: How does SpA develop in patients with HS? What treatment should be recommended?

Apart from the fact that $\mathrm{SpA}$ is generally an inflammatory disorder, the pathogenesis of SpA in HS patients is 
unclear. In contrast to other types of seronegative forms of $S p A$, an association with the histocompatibility antigen HLA-B27 in HS patients does not seem to exist [22, 27, 32]. Importantly, we did not observe any association between body height, body weight, BMI, smoking habits and the appearance of back pain or SpA, suggesting no major influence of lifestyle on the occurrence of back pain and SpA. Furthermore, the age at HS onset, duration of HS, and severity of skin alterations was similar in patient groups with and without back pain or SpA indicating that the skin alterations did not have an excessive influence on SpA or back pain. However, an aggravation of joint symptoms concurring with flares of skin disease has been reported by two studies $[24,26]$. All these facts might suggest that a genetic predisposition for SpA may exist in HS patients and that inflammatory skin alterations could induce $\mathrm{SpA}$ in these predisposed patients. The latter is supported by the observation that a surgical treatment of HS may improve SpA [22].

Successful systemic treatment in cases of symptomatic SpA in HS has been reported for non-steroidal anti-inflammatory drugs [24], systemic steroids [24], isotretinoin [23], sulphasalazine [25], cyclophosphamide [30] and anti-tumour necrosis factor (TNF) therapy [24, 33]. In fact, Lim et al. [24] described an HS patient with SpA who was asymptomatic and free of any skin lesions after treatment with adalimumab. Recently, anti-TNF drugs have proven effective in the therapy of severe cases of HS $[34,35]$. Moreover, a high degree of spinal inflammation visible on MRI is predictive of a successful response to anti-TNF therapy $[36,37]$. These findings suggest a positive effect of anti-TNF therapy in patients with severe HS also suffering from SpA but controlled studies need to be conducted to ascertain this assumption.

\section{Limitations of the Study}

Some biases result from the study design, such as the main recruitment of moderate to severe cases in our ter- tiary centre for HS. Also, in the MRI study only patients with HS located in the groins, buttocks and the perianal area were included, leaving out patients with merely axillary involvement. A further limitation of our study is the retrospective design leading to a lack of clinical data, specifically an arthritis activity score.

\section{Conclusions}

Patients suffering from HS of the groin, buttocks or perianal area are at high risk of developing SpA. This finding adds another aspect to the number of disorders lately found to be associated with HS and helps to understand HS as a systemic inflammatory disease. Patients with HS should be monitored for inflammatory joint pain and when clinical symptoms occur, the possibility of SpA should be ruled out ideally by MRI scanning. Active SpA in HS should be treated - preferably as part of a prospective investigation.

\section{Acknowledgements}

The authors acknowledge Annette Buss, Brigitte Ketel, and Beate Pust for their steady excellent technical assistance.

\section{Statement of Ethics}

Both substudies presented in this paper were approved by the ethical review board of the Charité University Hospital, Berlin, Germany.

\section{Disclosure Statement}

The authors declare no conflicts of interest.

\section{References}

1 Meixner D, Schneider S, Krause M, Sterry W: Acne inversa. J Dtsch Dermatol Ges 2008;6: 189-196.

2 Alikhan A, Lynch PJ, Eisen DB: Hidradenitis suppurativa: a comprehensive review. J Am Acad Dermatol 2009;60:539-561; quiz 562533.

3 Jemec GB, Heidenheim M, Nielsen NH: The prevalence of hidradenitis suppurativa and its potential precursor lesions. J Am Acad Dermatol 1996;35:191-194.

Spondyloarthropathy in Hidradenitis Suppurativa
4 Revuz JE, Canoui-Poitrine F, Wolkenstein P, Viallette C, Gabison G, Pouget F, Poli F, Faye O, Roujeau JC, Bonnelye G, Grob JJ, BastujiGarin S: Prevalence and factors associated with hidradenitis suppurativa: results from two case-control studies. J Am Acad Dermatol 2008;59:596-601.

5 Nazary M, van der Zee HH, Prens EP, Folkerts G, Boer J: Pathogenesis and pharmacotherapy of hidradenitis suppurativa. Eur J Pharmacol 2011;672:1-8.
6 Sartorius K, Killasli H, Oprica C, Sullivan A, Lapins J: Bacteriology of hidradenitis suppurativa exacerbations and deep tissue cultures obtained during carbon dioxide laser treatment. Br J Dermatol 2012;166:879-883.

7 Jahns AC, Killasli H, Nosek D, Lundskog B, Lenngren A, Muratova Z, Emtestam L, Alexeyev OA: Microbiology of hidradenitis suppurativa (acne inversa): a histological study of 27 patients. APMIS 2014;122:804-809. 
8 Wolk K, Warszawska K, Hoeflich C, Witte E, Schneider-Burrus S, Witte K, Kunz S, Buss A, Roewert HJ, Krause M, Lukowsky A, Volk HD, Sterry W, Sabat R: Deficiency of IL-22 contributes to a chronic inflammatory disease: pathogenetic mechanisms in acne inversa. J Immunol 2011;186:1228-1239.

9 Sabat R, Chanwangpong A, Schneider-Burrus S, Metternich D, Kokolakis G, Kurek A, Philipp S, Uribe D, Wolk K, Sterry W: Increased prevalence of metabolic syndrome in patients with acne inversa. PLoS One 2012; 7:e31810.

10 Tzellos T, Zouboulis CC, Gulliver W, Cohen AD, Wolkenstein P, Jemec GB: Cardiovascular disease risk factors in patients with hidradenitis suppurativa: a systematic review and meta-analysis of observational studies. $\mathrm{Br} \mathrm{J}$ Dermatol 2015;173:1142-1155.

11 Khan MA: Update on spondyloarthropathies. Ann Intern Med 2002;136:896-907.

12 Poddubnyy D, Haibel H, Listing J, MarkerHermann E, Zeidler H, Braun J, Sieper J, Rudwaleit M: Cigarette smoking has a dose-dependent impact on progression of structural damage in the spine in patients with axial spondyloarthritis: results from the German Spondyloarthritis Inception Cohort (GESPIC). Ann Rheum Dis 2013;72:14301432.

13 Dougados M, Demattei C, van den Berg R, Hoang VV, Thevenin F, Reijnierse M, Loeuille D, Feydy A, Claudepierre P, van der Heijde D: Rate and predisposing factors of sacroiliac radiographic progression after a 2 years followup period in recent onset spondyloarthritis. Arthritis Rheumatol 2016;68:1904-1913.

14 Maas F, Arends S, van der Veer E, Wink F, Efde M, Bootsma H, Brouwer E, Spoorenberg A: Obesity is common in axial spondyloarthritis and is associated with poor clinical outcome. J Rheumatol 2016;43:383-387.

15 Sartorius K, Lapins J, Emtestam L, Jemec GB: Suggestions for uniform outcome variables when reporting treatment effects in hidradenitis suppurativa. Br J Dermatol 2003;149: 211-213.

16 Sartorius K, Emtestam L, Jemec GB, Lapins J: Objective scoring of hidradenitis suppurativa reflecting the role of tobacco smoking and obesity. Br J Dermatol 2009;161:831-839.
17 Hurley AA: Axillary Hyperhidrosis, Apocrine Bromhidrosis, Hidradenitis Suppurativa, and Familial Benign Pemphigus: Surgical Approach. New York, Dekker, 1989.

18 Kurzen H, Kurokawa I, Jemec GB, Emtestam L, Sellheyer K, Giamarellos-Bourboulis EJ, Nagy I, Bechara FG, Sartorius K, Lapins J, Krahl D, Altmeyer P, Revuz J, Zouboulis CC: What causes hidradenitis suppurativa? Exp Dermatol 2008;17:455-456; discussion 457472.

19 Hermann KG, Braun J, Fischer T, Reisshauer $\mathrm{H}$, Bollow M: Magnetic resonance tomography of sacroiliitis: anatomy, histological pathology, MR morphology, and grading (in German). Radiologe 2004;44:217-228.

20 Hermann KG, Bollow M: Magnetic resonance imaging of the axial skeleton in rheumatoid disease. Best Pract Res Clin Rheumatol 2004; 18:881-907.

21 Leybishkis B, Fasseas P, Ryan KF, Roy R: Hidradenitis suppurativa and acne conglobata associated with spondyloarthropathy. Am J Med Sci 2001;321:195-197.

22 Rosner IA, Richter DE, Huettner TL, Kuffner GH, Wisnieski JJ, Burg CG: Spondyloarthropathy associated with hidradenitis suppurative and acne conglobata. Ann Intern Med 1982;97:520-525.

23 Libow LF, Friar DA: Arthropathy associated with cystic acne, hidradenitis suppurativa, and perifolliculitis capitis abscedens et suffodiens: treatment with isotretinoin. Cutis 1999; 64:87-90.

24 Lim DT, James NM, Hassan S, Khan MA: Spondyloarthritis associated with acne conglobata, hidradenitis suppurativa and dissecting cellulitis of the scalp: a review with illustrative cases. Curr Rheumatol Rep 2013;15:346.

25 Thein M, Hogarth MB, Acland K: Seronegative arthritis associated with the follicular occlusion triad. Clin Exp Dermatol 2004;29: 550-552.

26 Bhalla R, Sequeira W: Arthritis associated with hidradenitis suppurativa. Ann Rheum Dis 1994;53:64-66.

27 Ellis BI, Shier CK, Leisen JJ, Kastan DJ, McGoey JW: Acne-associated spondylarthropathy: radiographic features. Radiology 1987;162:541-545.
28 Poddubnyy D, Gaydukova I, Hermann KG, Song IH, Haibel H, Braun J, Sieper J: Magnetic resonance imaging compared to conventional radiographs for detection of chronic structural changes in sacroiliac joints in axial spondyloarthritis. J Rheumatol 2013;40: 1557-1565.

29 Rudwaleit M, Jurik AG, Hermann KG, Landewe R, van der Heijde D, Baraliakos X, Marzo-Ortega H, Ostergaard M, Braun J, Sieper J: Defining active sacroiliitis on magnetic resonance imaging (MRI) for classification of axial spondyloarthritis: a consensual approach by the ASAS/OMERACT MRI group. Ann Rheum Dis 2009;68:1520-1527.

30 Abid N, Opran A, Rosner F: Hidradenitis suppurativa complicated by erosive arthropathy and ulcerative keratitis. J Clin Rheumatol 1999;5:29-31.

31 Richette P, Molto A, Viguier M, Dawidowicz K, Hayem G, Nassif A, Wendling D, Aubin F, Liote F, Bachelez H: Hidradenitis suppurativa associated with spondyloarthritis - results from a multicenter national prospective study. J Rheumatol 2014;41:490-494.

32 Rosner IA, Burg CG, Wisnieski JJ, Schacter BZ, Richter DE: The clinical spectrum of the arthropathy associated with hidradenitis suppurativa and acne conglobata. J Rheumatol 1993;20:684-687.

33 Scheinfeld N: Treatment of coincident seronegative arthritis and hidradenitis suppurativa with adalimumab. J Am Acad Dermatol 2006;55:163-164.

34 Miller I, Lynggaard CD, Lophaven S, Zachariae C, Dufour DN, Jemec GB: A double-blind placebo-controlled randomized trial of adalimumab in the treatment of hidradenitis suppurativa. Br J Dermatol 2011;165:391-398.

35 Kimball AB, Kerdel F, Adams D, Mrowietz U, Gelfand JM, Gniadecki R, Prens EP, Schlessinger J, Zouboulis $\mathrm{CC}$, van der Zee $\mathrm{HH}$, Rosenfeld M, Mulani P, Gu Y, Paulson S, Okun M, Jemec GB: Adalimumab for the treatment of moderate to severe hidradenitis suppurativa: a parallel randomized trial. Ann Intern Med 2012;157:846-855.

36 Baraliakos X, Braun J: Opinion: perspectives on imaging in axial spondyloarthritis. Nat Rev Rheumatol 2013;9:498-502.

37 Sieper J: Treatment challenges in axial spondylarthritis and future directions. Curr Rheumatol Rep 2013;15:356. 